\title{
Forest pasturing of livestock in Norway: effects on spruce regeneration
}

\author{
Olav Hjeljord • Trond Histøl $\bullet$ Hilde Karine Wam
}

Received: 2013-06-10; $\quad$ Accepted: 2013-09-10

(C) Northeast Forestry University and Springer-Verlag Berlin Heidelberg 2014

\begin{abstract}
Forest pasturing of free-roaming livestock is a common practice in many parts of the world, but knowledge on how it affects tree regeneration in boreal forests is lacking. We mapped tree density, livestock site use and accumulated damage to young trees of commercial interest (Norway spruce, Picea abies L. Karst.) on 56 clearcuts inside and outside a fenced forest area used for livestock pasturing in Ringsaker, Norway. Inside the fence $56 \pm 1.8 \%$ of spruce trees were damaged compared to $37 \pm 3.4 \%$ outside. Proportion of damaged spruce trees was positively related to cattle use of the clearcut, but not so for sheep. On the most intensively used clearcuts, four out of five trees were damaged. The density of deciduous trees was five times lower inside compared to outside of the fence (varying with plant species). While livestock grazing may reduce resource competition in favour of spruce, the current animal density clearly is impeding forest regeneration in the study area.
\end{abstract}

Key words: browsing, cattle, damage, timber, sheep, ungulate

\section{Introduction}

Forest pasturing of free-roaming livestock is extensive in many parts of the world, with various levels of success concerning integration with other stakeholder interests (Asner et al. 2004). In Norway, the tradition dates back at least 5000 years (Hjelle et al.

Project Funding: Research was partly funded by the Research Council of Norway, project \#215647/E40 (Intensified harvesting of forests - implications for enterprises related to wild and domestic ungulates).

The online version is available at http://www.springerlink.com

\section{Olav Hjeljord}

Norwegian University of Life Sciences, Department of Ecology and Natural Resource Management, Box 5003, 1432 Ås, Norway.

Trond Histøl, Hilde Karine Wam ( $\triangle$ )

Norwegian Institute for Agricultural and Environmental Research, Organic Food and Farming Division, Gunnarsveg 6, 6630 Tingvoll, Norway. Email: hilde.wam@bioforsk.no; phone: +4792010746

Corresponding editor: Hu Yanbo
2006), and the associated easements are deeply rooted in Norwegian customary practice. However, as commercial forces encourage intensified agricultural production (Pender 1998), conflicts with other stakeholders are increasing.

In Norway, the number of animal farms has dropped from 150000 to 30000 in 50 years, and continues to decline at a steady rate of about 4\% per year (Statistics Norway 2012a). While the load of forest pasturing is going down at the national level (Austrheim et al. 2011), it is locally intensified. The remaining farms keep increasingly larger herds, and the average herd size of sheep and cattle on Norwegian farms currently is five times what it was 50 years ago. Furthermore, there is an ongoing shift from sheep and dairy cows to heavier breeds of beef cattle (Statistics Norway 2012b). The latter, such as Charolaise and Simmental, weigh up to $30 \%$ more than the Norwegian Red Cattle (Mason 1996). Beef cattle are also kept in a manner that more strongly enforces social cohesion, for example by herd keeping and letting calves suckle. This change in herd structure is expected to make grazing more concentrated (Arnold and Dudzinski 1978; Sowell et al. 1999).

It is well established that livestock grazing reduces regrowth of herbaceous and deciduous plants after forest clearing (Östlund et al. 1997; Belsky and Blumenthal 1997). In the perspective of commercial forestry this is considered positive because it reduces competition for nutrients, water and light (Zimmerman and Neuenschwander 1984; Prolux and Mazumder 1998). However, if the load of livestock becomes too high, their grazing, trampling and bedding may lead to erosion, soil packing and tree damage (Fleischner 1994; Hester et al. 2000). Like for all exploitation of natural resources, forest pasturing should be sustainable, i.e. animal numbers must balance other forest ecosystem services, also in a long term perspective.

While many studies have addressed the sustainability of livestock grazing in tropical and temperate forests (see Rook et al. 2004 for a review), studies are almost completely lacking for the boreal forests of the northern hemisphere. In Scandinavia, the few studies there is also have limited data and the publications are not readily available (e.g., Bjor and Graffer 1963). This knowledge gap needs to be filled in order to regulate the grazing intensity in a sustainable manner. 
In this study we mapped tree density, livestock site use and accumulated damage to young trees of commercial interest (Norway spruce, Picea abies L. Karst.) on 56 clearcuts inside and outside an area of livestock grazing in Ringsaker, Norway. A fenceline crosses the terrain irrespectively of vegetation type, soil fertility, topography and forestry practice, thereby creating a valuable experimental setting. We hypothesized that (1) tree recruitment would be lower and (2) damage levels would be higher inside the fence compared to outside, and (3) damage levels would be positively related to livestock site use.

\section{Materials and methods}

\section{Study area}

The Ringsaker Common Lands is situated in the county of Hedmark in southeastern Norway (UTM $278860^{\prime} \mathrm{E}, 6765400^{\prime} \mathrm{N}$ ). The study area is located on the lower (200-400 m.a.s.) west-facing slopes of the major river valley Mjøsa-Glomma. The climate is continental with cold winters (average temperature in February is $-8^{\circ} \mathrm{C}$ ) and warm summers (average temperature in July is $15^{\circ} \mathrm{C}$ ). Average yearly precipitation is $590 \mathrm{~mm}$, with highest levels in July and August. Snow generally stays on the ground from late October until mid April.

The forest is typical of the boreal coniferous zone of western Norway with spruce as the dominating tree species (Påhlsson 1984), with intermittent mixes of Scots pine (Pinus sylvestris L.) and deciduous trees (see result section). The field layer is species poor compared to adjacent regions, with a dominance of bilberry (Vaccinum myrtillus L.) in older forest and grasses (mainly wavy hair grass Deschampsia flexuosa L. and Calamagrostis spp.) on clearcuts (Fig. 1). In the intermediate growth stages, most vascular plants disappear due to the dense spruce causing space light to reach the forest floor. The forests of the area are subject to intensive commercial forestry, with practically all logging carried out as clearcutting of 80-100 year old stands. Clearcuts are generally in the range of one to three ha and almost exclusively regenerated by planting.

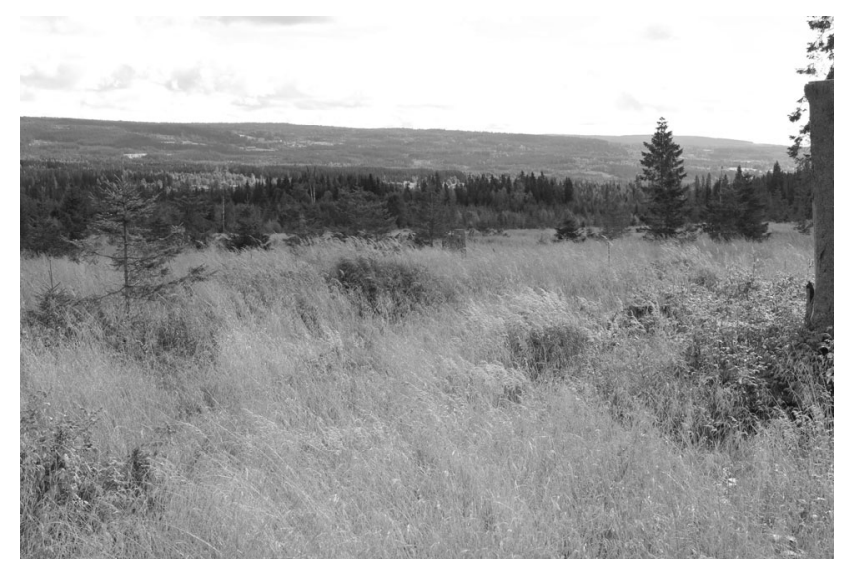

Fig. 1: Clearcuts in Ringsaker, Norway, are species poor, with planted spruce and a dominance of grasses (mainly Deschampsia spp. and Calamagrostis spp.).
The study area has a long tradition of forest pasturing of livestock. Approximately 50000 ha is fenced off into one continuous rangeland area, of which 25000 ha is productive forest, the remaining being mountain range. The number of sheep (Ovis aries L., sows and lambs) has remained stabile at about 15000 animals ( $0.6 \mathrm{ha}^{-1}$ of forest land) during the last two decades. The number of cattle (Bos taurus L.) has increased from a historical low of 500 animals in $1995\left(0.02 \mathrm{ha}^{-1}\right)$ to a current $1800\left(0.08 \mathrm{ha}^{-1}\right)$. In 1995 all the cattle were of dairy breeds (mainly heifers and barren cows of the Norwegian Red Cattle), and in 2012 approximately $75 \%$ of the cattle were of various imported beef breeds. The grazing season runs from medio June to medio September. The presence of wild ungulates (mainly moose Alces alces L., and some roe deer Capreolus capreolus L.) is negligible inside the livestock fence in summer (10 moose faeces/ha versus 380 for cattle, this study), but more prevalent outside the fence (60 moose faeces/ha).

\section{Data collection}

The study was conducted in September 2012. By doing the survey in late summer we covered the complete pasturing season, which runs from June to September. Sites to be surveyed were selected across all the forested area inside the livestock fence as well as in adjacent areas outside the fence. All sites consisted of younger clearcuts (development class II, i.e. 5-15 years since cutting, mean tree height up to 10-12 m, Tomter 1999) on similar soil fertility (G14 and G17, Tveite 1977). Apart from planting, the study sites had not been subject to silviculture treatment, such as brush control or soil scarification. A list of all available study sites was obtained from the data bases of the regional forest owners' association Mjøsen Skog SA.

Because we wanted to estimate the average level of forest damage, but also be able to relate the level of forest damage to the level of livestock use, we selected sites to be surveyed in two ways: (1) a randomized sample drawn from all available sites; and 2) a targeted sample, representing the largest possible gradient in livestock use. These sites were selected by the local managers based on the guideline that low livestock use is indicated by $<10 \%$ replanting (i.e. replacing a previously planted sapling that has died or disappeared), and high livestock use is indicated by $>50 \%$ replanting. Sites outside the fence (no livestock) were used as controls. The study design was thus balanced on three site types: random inside, targeted inside and random outside, aiming for a sample size of at least 15 sites per type.

At each sampling site we laid out 2-m wide transects forming a triangle, with the corners placed about one third the clearcut length in from the clearcut edge. The length of the transect triangles therefore varied with clearcut size. On average we walked $234 \pm 32 \mathrm{~m}$ per site (covering $468 \mathrm{~m}^{2}$ ). Along each transect we recorded: (1) tree density, i.e. the number of tree saplings. All trees $>30 \mathrm{~cm}$ tree height were counted, and recorded to species. Lower saplings are covered in the field vegetation, and therefore seldom intentionally browsed (Wam et al. 2010); (2) livestock site use, as indexed by counting faeces along the transect (Bennett et al. 1940); and (3) forest damage, defined as the proportion 
of spruce trees that showed sign of damage. We did not distinguish between age, types or causes of damage. Because sites were selected to be similar outside and inside the fence (apart from the presence of livestock), we attribute differences in the damage level to livestock activity. We defined damage as (a) broken leader shoot/main stem, (b) wounds in the bark, roots or inner structures, (c) crown deviations (lost, dead or dying parts), or (d) tree axis tilted $>25 \%$ from perpendicular to the base.

Data analyses

We analyzed differences between sites with ordinary $t$-tests as all parameters were normally distributed. In the reported $t_{n}$ statistics (two-sided), $n$ is the number of non-zero observations minus the number of groups. We used linear regression to check for correlative relationships between livestock use and the proportion of damaged spruce trees on a clearcut. Three extreme outliers in parameters pertaining to tree density were omitted from part of the analyses; one stemming from a clearcut with delayed planting (the site had only 170 spruce trees/ha), and two stemming from clearcuts with unusually high number of spruce trees (4250 and 5680 trees/ha). The statistical analyses were run in MINITAB statistical software (release 15.1.1.0, MINITAB Inc. 2007). All central measures are given as mean \pm SE if not otherwise indicated.

\section{Results}

Inside the fence, none of the parameters of interest differed between the random sites and the targeted sites, which were selected by the managers (cattle density $t_{37}=-0.1, p=0.894$; sheep density $t_{37}=0.4, p=0.721$; tree density (deciduous and pine) $t_{37}$ $=0.1, p=0.824$; spruce density $t_{35}=-0.3, p=0.792$; spruce damage $t_{35}=-0.6, p=0.531$ ). The targeted and the random sites are therefore pooled.

Tree density

There was a strong tendency of lower spruce density inside the fence $\left(t_{52}=-1.8, p=0.093\right)$, compared to the outside. The density of other trees (deciduous species and pine) was significantly lower inside the fence compared to outside $\left(t_{52}=-4.8, p \leq 0.001\right)$. Overall the ratio was approximately 1: $5(474 \pm 110$ trees ha inside versus $2594 \pm 521$ trees ha outside), but this varied with species (Fig. 2). For rowan (Sorbus aucuparia, L.), for example, it was more than 1: 15. Most of the deciduous trees were patchily distributed, i.e. found predominantly on a few study sites.

\section{Livestock site use}

We found livestock faeces on 39 out of 40 sites inside the fence. There were $380 \pm 62$ faeces per ha from cattle and $295 \pm 54$ faeces per ha from sheep. As expected, we found no livestock faeces outside the fence.

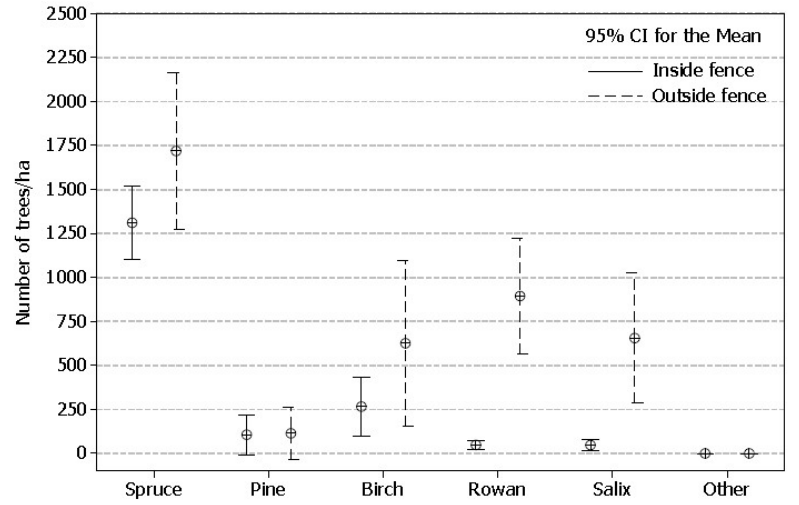

Fig. 2: Tree density (tree height $30-300 \mathrm{~cm})$ on clearcuts $(5-15$ years since cutting, soil fertility G14-G17), inside and outside a fence delimiting forest grazing of livestock (approximately 0.6 sheep and 0.08 cattle per ha) in Ringsaker, Norway 2012.

Forest damage

There was substantially more damage to young spruce trees inside the fence compared to the outside $\left(t_{54}=5.2, p \leq 0.001\right)$ (Fig. $3)$. Outside the fence the percentage of damaged trees ranged from $9 \%$ to $51 \%$, versus from $33 \%$ to $82 \%$ inside the fence. Damage levels were positively related to cattle use of the clearcut (density of faeces) $\left(R^{2}=29.3, \mathrm{df}=34, p \leq 0.001\right)$ (Fig. 4), but not so for sheep $\left(R^{2}=6.2, \mathrm{df}=34, p=0.144\right)$.

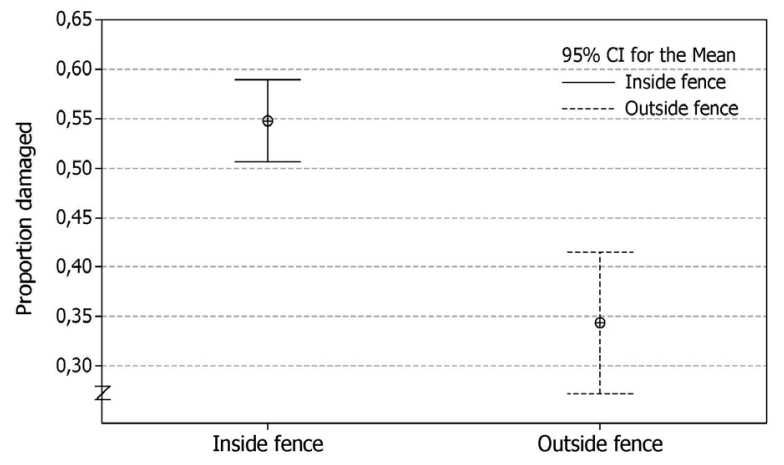

Fig. 3: Proportion of damaged young spruce trees (tree height 30-300 $\mathrm{cm}$ ) on clearcuts (5-15 years since cutting, soil fertility G14-G17), inside and outside a fence delimiting forest grazing of livestock (approximately 0.6 sheep and 0.08 cattle per ha) in Ringsaker, Norway 2012.

\section{Discussion}

Livestock grazing clearly was hindering forest regeneration in Ringsaker. The density of young spruce trees was reduced by at least $22 \%$ inside compared to outside the livestock fence (not adjusting for the fact that supplemental planting has been more prevalent inside the fence than outside, T. Uggen, pers. comm.). Furthermore, compared to the control area with no livestock, the proportion of damaged spruce trees was 1.6 times higher inside 
the fence. On the most affected sites inside the fence, four out of five spruce trees were damaged. Because the survey sites inside and outside the fence were selected to be otherwise similar, we can attribute the difference in damage levels to livestock activity.
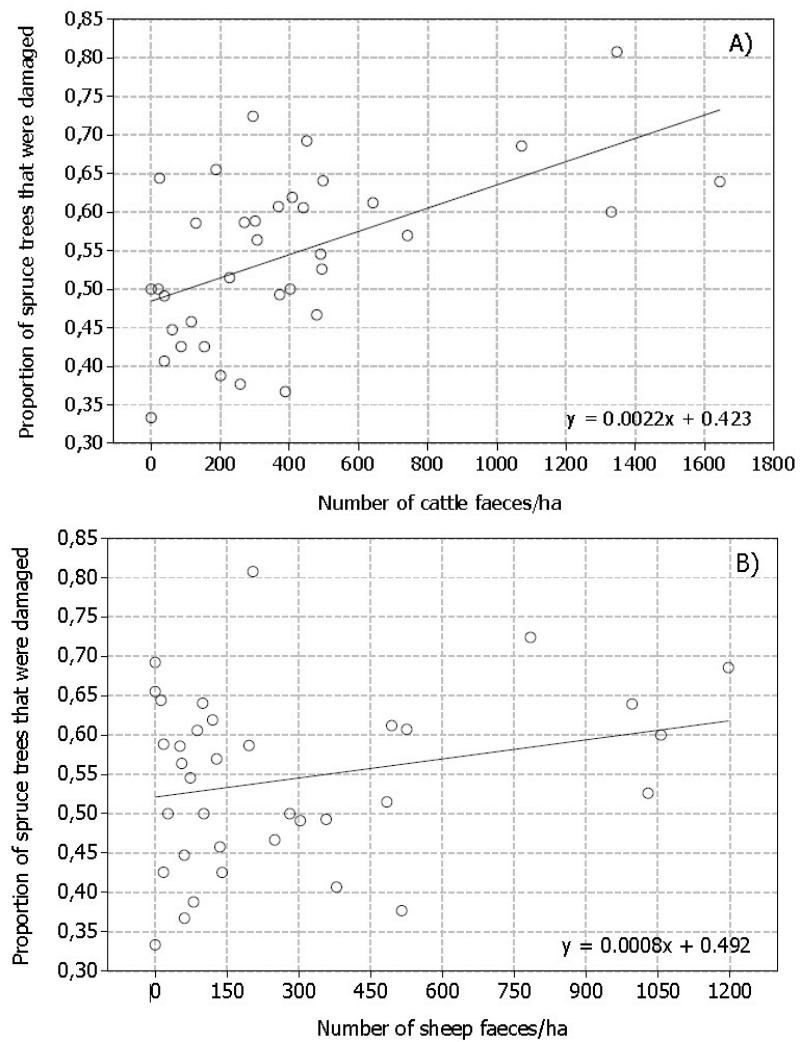

Fig. 4: Proportion of damaged young spruce trees (tree height 30-300 $\mathrm{cm}$ ) in relation to a) cattle and b) sheep use of clearcuts (forest age 5-15 years, soil fertility G14-G17), Ringsaker, Norway 2012.

Cattle site use was related to level of spruce damage. Albeit significant, the linear fit was not very strong. Sites with much damage were found at varying site use, but heavy site use was always associated with high damage levels. This pattern may be an effect of intensively used sites becoming progressively less favourable over the course of years. The cattle move on, but the damage remains. Because pellet counts as a proxy for animal activity is influenced by defecation- and decomposition rates (Neff 1968; Putman 1984), our data should not be directly extrapolated to other areas. Preferentially, future studies of livestock use of forests should include remote sensing of animal movement.

Our study suggests that high levels of tree damage from pasturing livestock in spruce forest can occur at lower animal densities than previously held. We are aware of only two comparable published studies in spruce forest (but see also Liss 1988). In the Swiss Alps, with $0.4-2.8$ livestock units of cattle (600 $\mathrm{kg}$ body weight) (LU) per ha, $12-55 \%$ of spruce trees were damaged by the animals after one summer, but none fatally (Mayer et al. 2006). In a series of studies in the 1950 s in Norway, $14 \%$ of spruce saplings were destroyed by livestock after 6 summers of grazing (up to $3.8 \mathrm{LU} / \mathrm{ha}$ ), and of the surviving saplings $26 \%$ had livestock-related damages (Bjor and Graffer 1963). The livestock density in our study was $<0.2 \mathrm{LU} / \mathrm{ha}$ but locally much higher, and the grazing period averaged 7 summers. We attribute at least $22 \%$ of lost spruce saplings, and $21 \%$ of damaged spruce trees, to livestock activity.

While spruce is the only tree of interest for commercial forestry in the Ringsaker area, deciduous trees (and pine) are important for other stakeholders (e.g., game providers and nonconsumptive interests). It should be noted that rowan and Salix spp. were practically non-existent inside the fence.

\section{Implications}

The Ringsaker study illustrates an important call to managers: As natural resources are becoming increasingly scarce, and the commercial exploitation of them more specialized, singlepurpose management is no longer sufficient. Optimal stocking of livestock and logging potential must be determined by an adaptive approach coupling not only economic, but also ecological and social aspects (e.g., Brunson 2012; Bestelmeyer and Briske 2012; Wam et al. 2012).

\section{References}

Arnold GW, Dudzinski ML. 1978. Ethology of free-ranging domestic animals. Amsterdam: Elsevier, p.198.

Asner GP, Elmore AJ, Olander LP, Martin RE, Harris AT. 2004. Grazing systems, ecosystem responses, and global change. Annual Review of Environment and Resources, 29: 261-299.

Austrheim G, Solberg EJ, Mysterud A. 2011. Spatio-temporal variation in large herbivore pressure in Norway during 1949-1999: has decreased grazing by livestock been countered by increased browsing by cervids? Wildlife Biology, 17: 286-298.

Belsky AJ, Blumenthal DM. 1997. Effects of livestock grazing on stand dynamics and soils in upland forests of the Interior West. Conservation Biology, 11: 315-327.

Bennett LJ, English PF, McCain R. 1940. A study of deer populations by use of pellet-group counts. Journal of Wildlife Management, 4: 398-403.

Bestelmeyer BT, Briske DD. 2012. Grand challenges for resilience-based management of rangelands. Rangeland Ecology \& Management, 65: 654-663.

Bjor K, Graffer H. 1963. Studies of forest pasturing in Norway. Scertrykk av forskning og forsøk i landbruket, 14: 121-365.

Brunson MW. 2012. The elusive promise of social-ecological approaches to rangeland management. Rangeland Ecology \& Management, 65 : 632-637.

Fleischner TL. 1994. Ecological costs of livestock grazing in western North America. Conservation Biology, 8: 629-644.

Hester AJ, Edenius L, Buttenschøn RM, Kuiters AT. 2000. Interactions between forests and herbivores: the role of controlled grazing experiments. Forestry, 73: 381-391.

Hjelle KL, Hufthammer AK, Bergsvik KA. 2006. Hesitant hunters: a review of the introduction of agriculture in western Norway. Environmental Archaeology, 11: 147-170. 
Liss BM. 1988. Influence of grazing livestock and wildlife on natural and artificial recruitment of mixed mountain forest in the eastern Bavarian Alps. Forstwissenschaftliches Centralblatt, 107: 14-25.

Mason IL. 1996. A world dictionary of livestock breeds, types and varieties ( $4^{\text {th }}$ ed). Wallingford: CABI Publishing, p.273.

Mayer AC, Stöckli V, Konold W, Kreuzer M. 2006. Influence of cattle stocking rate on browsing of Norway spruce in subalpine wood pastures. Agroforestry Systems, 66: 143-149.

Neff DJ. 1968. The pellet-group count technique for big game trend, census, and distribution: A review. Journal of Wildlife Management, 32: $597-614$.

Östlund L, Zackrisson O, Axelsson AL. 1997. The history and transformation of a Scandinavian boreal forest landscape since the $19^{\text {th }}$ century. Canadian Journal of Forest Research, 27: 1198-1206.

Påhlsson L. 1984. Naturgeografisk regioninndeling av Norden. Stocholm: Nordiska Ministerrådet, p.510.

Pender JL. 1998. Population growth, agricultural intensification, induced innovation and natural resource sustainability: An application of neoclassical growth theory. Agricultural Economics, 19: 99-112.

Prolux M, Mazumder A. 1998. Reversal of grazing impact on plant species richness in nutrient-poor vs. nutrient-rich ecosystems. Ecology, 79: 2581-2592.

Putman RJ. 1984. Facts from faeces. Mammal Review, 14: 79-97.

Rook AJ, Dumont B, Isselstein J, Osoro K, WallisDeVries MF, Parente K, Mills J. 2004. Matching type of livestock to desired biodiversity outcomes in pastures - a review. Biological Conservation, 119: 137-150.
Sowell BF, Mosley JC, Bowman JGP. 1999. Social behavior of grazing beef cattle: Implications for management. In: Proceedings of the American Society of Animal Science 1999, pp. 1-6.

Statistics Norway. 2012a. Statistikkbanken: subject 10, table 03688. (in Norwegian). Available at: http://statbank.ssb.no/statistikkbanken. [Access at 15-02-2013].

Statistics Norway. 2012b. Statistikkbanken: subject 10, table 03710. (in Norwegian). Available at: http://statbank.ssb.no/statistikkbanken. [Access1502-2013].

Tomter SM. 1999. Skog 2000. Statistikk over skogforhold og -ressurser i Norge. NIJOS rapport 7/99.

Tveite B. 1977. Site-index curves for Norway spruce (Picea abies (L.) Karst.). Norwegian Forest Research Institute, Report No. 33.1, p.84. (in Norwegian with English summary.

Wam HK, Hjeljord O, Solberg EJ. 2010. Differential forage use makes carrying capacity equivocal on ranges of Scandinavian moose (Alces alces). Canadian Journal of Zoology, 88: 1179-1191.

Wam HK, Pedersen HC, Hjeljord O. 2012. Balancing hunting regulations and hunter satisfaction: An integrated biosocioeconomic model to aid in sustainable management. Ecological Economics, 79: 89-96.

Zimmerman GT, Neuenschwander LF. 1984. Livestock grazing influences on community structure, fire intensity, and fire frequency within the Douglas-fir/ninebark habitat type. Journal of Range Management, 37: $104-110$. 